\section{Clinical outcomes of Ahmed glaucoma valve in anterior chamber versus ciliary sulcus}

\begin{abstract}
Purpose To evaluate the outcomes of Ahmed glaucoma valve (AGV) tube insertion through the anterior chamber angle (ACA) or through the ciliary sulcus (CS).

Patients and methods In this case-control study, we retrospectively reviewed the charts of consecutive glaucoma patients who had undergone AGV implantation either through the ACA or the CS between March 2009 and December 2014. The main outcome measures were intraocular pressure (IOP), number of glaucoma medications prescribed, best corrected visual acuity (BCVA), glaucoma type, success rate, complications, and survival ratios. Statistical analysis was carried out using SPSS.

Results There were 68 eyes in the ACA group and 35 eyes in the CS group. There were no significant differences between the groups for age, sex, laterality, IOP, preoperative glaucoma medication number, BCVA or glaucoma type $(P>0.05)$. The postoperative follow-up period was

\section{Introduction}

The indications for use of glaucoma drainage devices (GDDs) have broadened in recent years, with some clinicians preferring GDDs as a primary surgical treatment. One study reports an annual increase in the number of GDDs placed between the years of 1995 and 2004, totaling $184 \% .{ }^{1}$ One of the main complications of GDD implantation into the anterior chamber angle (ACA) is corneal endothelial decompensation. The frequency of corneal complications following GDD implantation with tube insertion into the ACA has been reported to be between 7 and $27 \% .^{2-5}$ To overcome these complications, tube insertion through the ciliary sulcus (CS) has been considered as an alternative in pseudophakic/aphakic patients or in patients with peripheral anterior synechiae. ${ }^{6-13}$ In this study, we proposed to compare the long-term clinical results of two methods: ACA insertion and CS insertion of an Ahmed glaucoma valve (AGV) tube.
\end{abstract} $27.2 \pm 16.5$ months and $30.2 \pm 17.7$ months for

Dünyagöz Ankara Hospital, Glaucoma Department, Ankara, Turkey

Correspondence: A Bayer, Professor of Ophthalmology, Dünyagöz Ankara Hospital, Glaucoma Department, Tunus cad, No. 28, Kavaklidere, Ankara, Turkey Tel: +90 3124167000 ; Fax: +90 3124179337 E-mail: atillabayer@ hotmail.com the ACA and the CS groups $(P=0.28)$; IOP values were significantly reduced at the last visit to $16.4 \pm 7.2 \mathrm{~mm} \mathrm{Hg}$ and $14.4 \pm 6.8 \mathrm{~mm} \mathrm{Hg}$. The difference in the last-visit IOP between the groups was not significant $(P=0.06)$, but the IOP reduction ratio was higher in the CS group $(P=0.03)$. There was no significant difference in the number of postoperative medications $(P=0.18)$. Postoperative complications were similar, but the incidence of flat anterior chamber was higher in the ACA group $(P=0.05)$.

Conclusions The use of an AGV can control IOP in the majority of cases whether placed in the ACA or the CS. The IOP reduction ratio seemed to be higher in the CS group. Eye (2017) 31, 608-614; doi:10.1038/eye.2016.273; published online 16 December 2016
A Bayer and M Önol

\section{Materials and methods}

This was a single center, retrospective casecontrol study. The study was approved by the World Eye Hospital's Institutional Review Board. Written informed consent was obtained from all patients before all surgical procedures. We reviewed the charts of all consecutive patients who had undergone AGV implantation (Model FP-7; New World Medical, Rancho Cucamonga, CA, USA) either through the ACA or the CS between March 2009 and December 2014. Patients were included if they had at least 1 year of follow-up and were excluded if they had an anterior chamber intraocular lens (IOL), had bullous keratopathy or had received previous GDD implantation. 
Surgical procedures were performed by one of the two authors (AB or MÖ) Both surgeons performed proportionate numbers of ACA and CS tube implantation procedures.

The implantation was performed using either retrobulbar or general anesthesia. A 7-0 Vicryl clear cornea traction suture was placed. Fornix-based conjunctival and Tenon's capsule flap, and a limbal-based scleral flap of $4 \times 4 \mathrm{~mm}$ was prepared. After testing its patency by injecting balanced salt solution, the AGV was fixed to the sclera $8-10 \mathrm{~mm}$ from the limbus with 2 interrupted 6-0 nylon sutures (Ethicon, Johnson and Johnson, New Brunswick, NJ, USA). For ACA implantation, a paracentesis was created through which Viscoat (Alcon Laboratories Inc., Fort Worth, TX, USA) was injected into the anterior chamber. The tube was trimmed to lie 1-2 $\mathrm{mm}$ past the surgical limbus and was cut in a bevel-up manner. It was then inserted through a sclera fistula that was created with a $23 \mathrm{G}$ needle.

For CS implantation, a paracentesis was created through which Viscoat was injected behind the iris in the planned quadrant. The tube was then trimmed to lie 1-2 mm past the surgical limbus and cut in a bevel-down manner. A scleral fistula was created with a $23 \mathrm{G}$ needle and the tube was inserted into the CS.

In both techniques, the tube was fixed to the sclera with a 10-0 nylon, and the exposed tube was covered with the scleral flap that was tied with 10-0 nylon. The Tenon's capsule and conjunctiva were sutured with 10-0 nylon. We used ACA implantation in pseudophakic eyes where there was a sclera-fixated IOL, weak zonules, or an extensive Soemmering's ring. In one patient with aphakia, the tube was implanted into the ACA as the patient had a pupillary membrane. In two phakic eyes with neovascular glaucoma that had extensive peripheral anterior synechia, the tube was implanted into the CS.

Postoperative therapy consisted of $0.3 \%$ ciprofloxacin eye drop qid, $1 \%$ prednisolone acetate eye drop qid, and $1 \%$ cyclopentholate eye drop bid. Ciprofloxacin and cyclopentholate eye drops were discontinued after 1 and 2 weeks, respectively. Topical prednisolone acetate was gradually reduced over 4-6 weeks.

The preoperative data, including the patient's age, sex, laterality, glaucoma medications, history of surgical glaucoma treatment, intraocular pressure (IOP) measured by Goldmann applanation tonometry or by Tonopen, best-corrected visual acuity (BCVA), and glaucoma type was recorded. We collected the postoperative data for glaucoma medications, IOP, BCVA, and postoperative complications on day 1 , days $3-5$, weeks 1,2 , and 3 , months $1,2,3,6,9,12$, and every 6 months thereafter.

Surgical failure was defined on the basis of the World Glaucoma Association Guidelines on Design and Reporting of Surgical Trials. ${ }^{14}$ These criteria were defined as IOP $>21 \mathrm{~mm} \mathrm{Hg}$ or $<20 \%$ reduction below baseline on two consecutive visits after 3 months, IOP $\leq 5 \mathrm{~mm} \mathrm{Hg}$ on two consecutive study visits after 3 months, repeat surgery for glaucoma, loss of light perception or removal, of the implant for any reason.

All the data collected in the study were inserted into an electronic database via Microsoft Excel 2007 (Microsoft Corporation, Redmond, WA, USA). Statistical analysis was performed using with IBM SPSS Statistics 21.0 (IBM Corp. Released 2012. IBM SPSS Statistics (for Windows, Version 21.0, Armonk, NY, USA). Snellen BCVA measurements were converted to the logarithm of the minimum angle of resolution (logMAR) VA equivalents for the purpose of the data analysis. ${ }^{15}$ Non-parametric tests were used since the case numbers was not equal between the groups. Comparisons between the ACA and CS groups were performed using the $\chi^{2}$-test for the categorical variables. Mann-Whitney $U$ test was used to compare the two groups, while Wilcoxon signed-rank test was used to compare the preoperative and postoperative parameters within each group. All the statistical tests were two-sided. The cumulative probability of success in both groups was calculated by the Kaplan-Meier survival analysis and the log-rank test. $P$-values of $<0.05$ were considered statistically significant.

\section{Results}

The study included 68 eyes from 68 patients who had undergone AGV implantation in the ACA and 35 eyes from 35 patients who had undergone AGV implantation in the CS. The follow-up period was $27.2 \pm 16.5$ months (mean \pm SD; range, $12-74 \mathrm{mo}$ ) and $30.2 \pm 17.7$ months (mean \pm SD; range, $12-76$ months) for the ACA and the CS groups, respectively. The difference was not significant. There was no significant difference between the groups for age, sex, laterality, preoperative glaucoma medication number, number of previous glaucoma surgeries, IOP, BCVA, or glaucoma type (Table 1). Lens status, defined as phakia, aphakia, and posterior chamber IOL was significantly different between the groups $(P<0.001)$.

The preoperative IOP was $36.9 \pm 10.8 \mathrm{~mm} \mathrm{Hg}$ (mean $\pm \mathrm{SD}$; range, $20-70 \mathrm{~mm} \mathrm{Hg}$ ) and $37.6 \pm 9.2 \mathrm{~mm} \mathrm{Hg}$ (mean $\pm \mathrm{SD}$; range, $19-58 \mathrm{~mm} \mathrm{Hg}$ ) in the ACA and the CS groups, respectively, with no significant difference between the groups (Table 2). These were significantly reduced at the last visit to $16.4 \pm 7.2 \mathrm{~mm} \mathrm{Hg}$ (mean $\pm \mathrm{SD}$; range, $6-56 \mathrm{~mm} \mathrm{Hg}$ ) in the ACA group and

$14.4 \pm 6.8 \mathrm{~mm} \mathrm{Hg}$ (mean $\pm \mathrm{SD}$; range, 3 to $32 \mathrm{~mm} \mathrm{Hg}$ ) in the CS group $(P<0.001)$. This represented a reduction of $53.63 \pm 16.9 \%$ (mean \pm SD; range, $-12 \%$ to $86 \%$ ) and $59.46 \pm 20.64 \%$ (mean \pm SD; range $8.6 \%$ to $91 \%$ ), respectively. While the difference in the last-visit IOP 
Table 1 The preoperative demographic data for anterior chamber angle and ciliary sulcus groups

\begin{tabular}{|c|c|c|c|}
\hline Characteristics & Anterior chamber angle group $\mathrm{n}=68$ & Ciliary sulcus group $\mathrm{n}=35$ & $\mathrm{P}$ \\
\hline Age (years), mean $\pm S D$ & $46.9 \pm 24.9$ & $40.9 \pm 22.2$ & 0.23 \\
\hline Sex $($ no. $(\%))$ & & & 0.20 \\
\hline Female & $28(41.1)$ & $16(45.7)$ & \\
\hline Male & $40(58.9)$ & $19(54.3)$ & \\
\hline Right eye (no. (\%)) & $38(55.8)$ & $20(57.1)$ & 0.83 \\
\hline Preoperative medications, mean \pm SD & $3.77 \pm 0.73$ & $3.67 \pm 0.87$ & 0.63 \\
\hline Previous glaucoma surgery number, mean \pm SD & $0.68 \pm 0.87$ & $0.55 \pm 0.70$ & 0.79 \\
\hline Lens status (no. (\%)) & & & 0.000 \\
\hline Phakic & $61(89.7)$ & $2(5.7)$ & \\
\hline Aphakic & $1(1.5)$ & $6(17.1)$ & \\
\hline PCIOL & $6(8.8)$ & $27(77.1)$ & \\
\hline $\mathrm{IOP}(\mathrm{mm} \mathrm{Hg})$, mean $\pm \mathrm{SD}$ & $36.9 \pm 10.8$ & $37.6 \pm 9.2$ & 0.54 \\
\hline $\mathrm{BCVA}(\log M A R)$, mean $\pm \mathrm{SD}$ & $0.99 \pm 0.69$ & $1.03 \pm 0.64$ & 0.68 \\
\hline Glaucoma diagnosis (no. $(\%))$ & & & 0.23 \\
\hline POAG & $17(25)$ & $11(31.4)$ & \\
\hline Childhood glaucoma & $15(22)$ & $2(5.7)$ & \\
\hline Neovascular & $10(14.7)$ & $4(11.4)$ & \\
\hline Pseudoexfoliative & $9(13.2)$ & $5(14.3)$ & \\
\hline Uveitic & $3(4.4)$ & $3(8.6)$ & \\
\hline Chronic angle-closure & $2(2.9)$ & $4(11.4)$ & \\
\hline Juvenile OAG & $4(5.9)$ & $1(2.9)$ & \\
\hline Traumatic & $3(4.4)$ & $1(2.9)$ & \\
\hline Other & $5(7.4)$ & $4(11.4)$ & \\
\hline
\end{tabular}

Abbreviations: BCVA, best corrected visual acuity; IOP, intraocular pressure; LogMAR, logarithm of the minimum angle of resolution; OAG, open-angle glaucoma; PCIOL, posterior chamber intraocular lens; POAG, primary open-angle glaucoma; SD, standard deviation.

Table 2 Last follow-up examination after Ahmed glaucoma valve implantation in anterior chamber angle and ciliary sulcus groups

\begin{tabular}{lccc}
\hline Characteristics & $\begin{array}{c}\text { Anterior chamber } \\
\text { angle group } \\
\mathrm{n}=68\end{array}$ & $\begin{array}{c}\text { Ciliary sulcus } \\
\text { group } \mathrm{n}=35\end{array}$ & $\mathrm{P}$ \\
\hline $\begin{array}{l}\text { Length of follow-up } \\
\text { (months), mean } \pm \mathrm{SD}\end{array}$ & $27.2 \pm 16.5$ & $30.2 \pm 17.7$ & 0.28 \\
& & & \\
IOP (mm Hg), mean $\pm S D$ & $36.9 \pm 10.8$ & $37.6 \pm 9.2$ & 0.54 \\
$\quad$ Preoperative & $16.4 \pm 7.2$ & $14.4 \pm 6.8$ & 0.06 \\
Postoperative & & & \\
& & & \\
Glaucoma medications, mean $\pm S D$ & $3.7 \pm 0.9$ & 0.63 \\
Preoperative & $3.8 \pm 0.7$ & $0.53 \pm 1.1$ & 0.18 \\
Postoperative & $0.84 \pm 1.3$ & & \\
& & & \\
BCVA (LogMAR), mean $\pm S D$ & $0.99 \pm 0.69$ & $1.03 \pm 0.64$ & 0.68 \\
$\quad$ Preoperative & $1.00 \pm 0.70$ & $1.05 \pm 0.71$ & 0.64 \\
Postoperative & & & \\
Surgical outcome & $57(83.8)$ & $29(85.3)$ & 0.84 \\
$\quad$ Success (no.(\%)) & $11(16.2)$ & $6(14.7)$ & \\
Failure (no.(\%)) &
\end{tabular}

Abbreviations: BCVA, best corrected visual acuity; IOP, intraocular pressure; LogMAR, logarithm of the minimum angle of resolution; $\mathrm{SD}$, sstandard deviation.

between the groups did not reach significance, the difference between the IOP reduction ratios was significant $(P=0.03)$. Figure 1 shows the mean preoperative IOP and the IOP at each of the postoperative

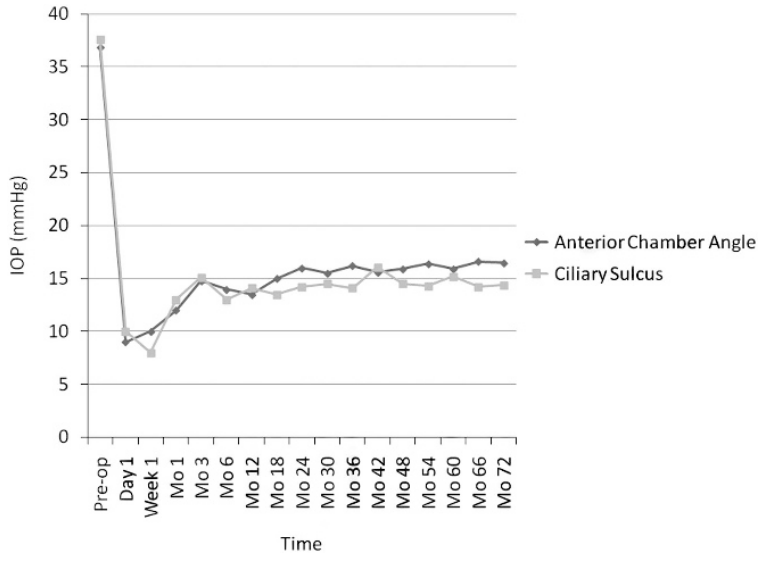

Figure 1 Preoperative and postoperative intraocular pressure (IOP) comparison between anterior chamber angle and the ciliary sulcus groups.

time points for the groups. Mean IOP did not differ significantly between the groups at any time point throughout the follow-up.

Figure 2 shows the Kaplan-Meier survival analysis for the two groups. The difference between the survival curves was not statistically significant.

The preoperative number of glaucoma medications in the $\mathrm{AC}$ and the $\mathrm{CS}$ groups was $3.8 \pm 0.7$ (mean $\pm \mathrm{SD}$; range, $2-5$ ) and $3.7 \pm 0.9$ (mean $\pm S D$; range, $1-6$ ), respectively. It was significantly reduced to $0.84 \pm 1.3$ (mean \pm SD; range, $0-4$ ) and $0.53 \pm 1.1$ (mean \pm SD; 


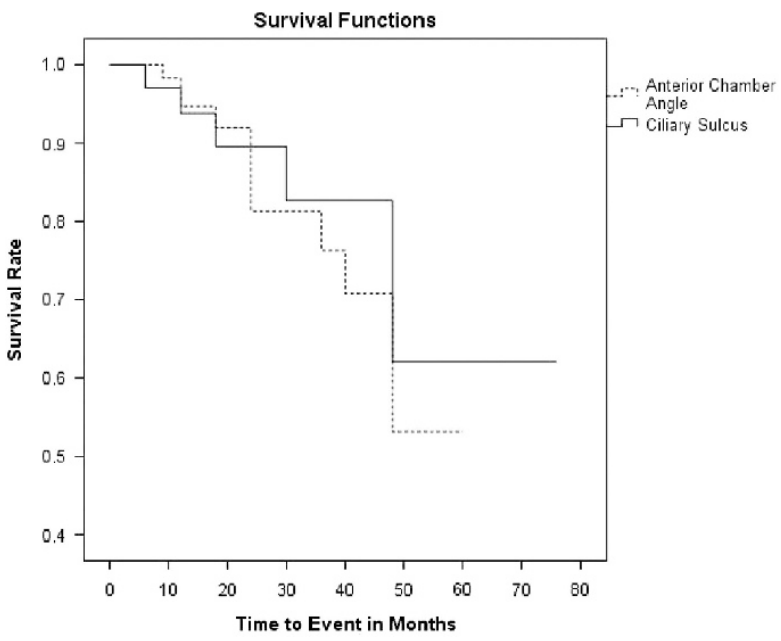

Figure 2 Kaplan-Meier survival curves after Ahmed glaucoma valve implantation in the anterior chamber angle and ciliary sulcus. The success rates were 98.3 and $97.1 \%$ at 6 months, 94.7 and $93.8 \%$ at 12 months, and 81.3 and $89.6 \%$ at 24 months, 76.3 and $82.7 \%$ at 36 months, 53.1 and $62 \%$ at 48 months, and 53.1 and $62 \%$ at 60 months in the anterior chamber angle and ciliary sulcus groups, respectively. The difference between the survival curves was not statistically significant $(P=0.77)$.

range, $0-5)$, respectively $(P<0.001)$. There was no significant difference in the number of medications used between the groups either before or after surgery.

For the ACA and the CS groups, the preoperative LogMAR was $0.99 \pm 0.69$ (mean \pm SD; range, $0-2)$ and $1.03 \pm 0.64$ (mean $\pm \mathrm{SD}$; range, $0-2$ ), respectively. The postoperative $\operatorname{LogMAR}$ was $1.00 \pm 0.70($ mean $\pm \mathrm{SD}$; range, $0-2$ ) and $1.05 \pm 0.71$ (mean $\pm S D$; range, $0-2$ ), respectively. There was no significant difference either between the groups or between preoperative and postoperative values.

The postoperative complications and reoperations for the two groups are summarized in Table 3. Hyphema was the most common complication in both the groups and was observed in a total of 12 eyes $(17.6 \%)$ in the ACA group, and 5 eyes $(14.3 \%)$ in the CS group. The difference between the groups was not significant. There were 8 eyes $(11.8 \%)$ that exhibited early postoperative shallow/flat anterior chamber in the ACA group and 1 eye (2.9\%) in the CS group. The difference between the groups was not significant. We did not find any statistically significant difference between the groups for other complications. Injection of intracameral viscoelastic for shallow/flat anterior chamber was performed in 7 eyes (10.3\%) in the ACA group, while affected eyes in the CS group gained normal anterior chamber depth without intervention. The difference between the groups was significant $(P<0.001)$. Other interventions and reoperations were similar between the groups.

\section{Discussion}

To the best of our knowledge, this is the first direct comparison between ACA and CS placement of a GDD tube. Previous studies have shown that CS insertion of tube shunts is a safe and effective alternative to ACA or pars plana insertion. ${ }^{7,12,13,16}$ Implantation into the CS in pseudophakic or aphakic patients could prevent the complications associated with ACA placement such as corneal decompensation.

As we anticipated, lens status was different between the two groups. There is no clear information about the effect of lens status on the success of tube implants. Broadway et al ${ }^{17}$ have reported that pseudophakia is a significant risk factor for failure in Molteno implants. However, in the Tube versus Trabeculectomy Study, lens status was not associated with treatment failure. ${ }^{18}$

In this study, the success rate was $83.8 \%$ in the ACA group and $85.3 \%$ in the CS group and was similar to that in the other long-term studies. ${ }^{19-21}$ In these studies, success rates ranged from 72 to $88 \%$, with a mean followup ranging from 14 to 25 months. In a series of AGV implantations using tube insertion into the CS, Weiner et $a^{13}$ reported that $91.7 \%$ of eyes had a final IOP of 5-21 mm Hg after a follow-up of 21.8 months. Eslami et $a l^{7}$ reported a success rate of $78.6 \%$, where success was defined as a final IOP $<21 \mathrm{~mm} \mathrm{Hg}$ with an overall reduction of $20 \%$, without the need for further surgery, and without loss of light perception. However, the direct comparison of the results obtained in different studies of the AGV is difficult since there are differences in the study populations, the distribution of glaucoma types, and differences in the definitions of clinical success.

The mean IOP and the number of glaucoma medications at final follow-up were similar in the two groups. However, the IOP reduction ratio was higher in the CS group. We cannot provide an explanation for this difference; as previously discussed, it cannot be explained by differences in lens status. The silicone tube itself may have direct mechanical or toxic effect on the ciliary body in the CS group, leading to a decrease in the secretion of aqueous.

Hyphema and shallow/flat anterior chamber were the most common complications. Weiner et $a l^{13}$ have reported that hyphema is more common in patients with CS tube insertion possibly due to the greater vascularization of the CS when compared with the angle or pars plana. In our study, the incidence of hyphema was similar between the groups. This ratio has previously been reported to range between 0.0 and $31.7 \% 5,7,13$ and the ratios we found (17.6 and $14.3 \%$ in the ACA and CS groups, respectively) is comparable to these. Although the ratio of flat anterior chamber was similar between the groups, the incidence of flat anterior chamber requiring 
Table 3 Postoperative complications and reoperations in anterior chamber angle and ciliary sulcus groups

\begin{tabular}{|c|c|c|c|}
\hline Complication & Anterior chamber angle group $\mathrm{n}=68$ & Ciliary sulcus group $\mathrm{n}=35$ & $\mathrm{P}$ \\
\hline Postoperative complications (no.(\%)) & & & 0.50 \\
\hline Hyphema & $12(17.6)$ & $5(14.3)$ & 0.70 \\
\hline Shallow or flat anterior chamber & $8(11.8)$ & $1(2.9)$ & 0.15 \\
\hline Corneal failure $^{\mathrm{a}}$ & $1(1.5)$ & 0 & 0.48 \\
\hline Choroidal effusion & $1(1.5)$ & $2(5.7)$ & 0.21 \\
\hline Tube/plate exposure & $2(2.9)$ & 0 & 0.31 \\
\hline Encapsulated bleb & $1(1.5)$ & $1(2.9)$ & 0.61 \\
\hline Tube obstruction & $1(1.5)$ & 0 & 0.48 \\
\hline Pigment dispersion & 0 & $1(2.9)$ & 0.16 \\
\hline Aqueous misdirection & 0 & $1(2.9)$ & 0.16 \\
\hline Tube migration & 0 & $1(2.9)$ & 0.16 \\
\hline Phtisis & 0 & $1(2.9)$ & 0.16 \\
\hline Total & $26(38.2)$ & $13(37.1)$ & 0.38 \\
\hline \multicolumn{4}{|l|}{ Reoperation } \\
\hline Injection of intracameral viscoelastic & $7(10.3)$ & 0 & 0.05 \\
\hline Injection of intracameral tPA & 0 & $1(2.9)$ & 0.35 \\
\hline Graft for conjunctival erosion & $2(2.9)$ & 0 & 0.44 \\
\hline Cyclodestruction & 0 & $1(2.9)$ & 0.35 \\
\hline Bleb revision for encapsulation & $2(2.9)$ & $1(2.9)$ & 0.73 \\
\hline Tube revision for obstruction & $1(1.5)$ & 0 & 0.66 \\
\hline PPV+irido-zonulo-hyaloidotomy & 0 & $1(2.9)$ & 0.35 \\
\hline Total & 12 (17.6) & $4(11.4)$ & 0.17 \\
\hline
\end{tabular}

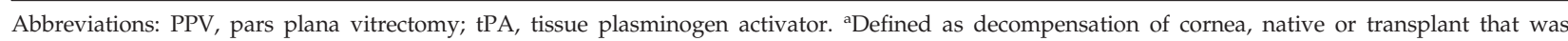
optically clear preoperatively.

reformation with viscoelastic was higher in the ACA group. This ratio has been reported to be between 0.0 and $20 \%, 5,17,22$ and was found to be $10.2 \%$ in our ACA group. We suggest that there are some possible explanations for the increased rate of anterior chamber reformation in the ACA group. The first and most logical explanation is that the anterior chamber is deeper in pseudophakic or aphakic eyes when compared with the phakic eyes. The second explanation is that the threshold for reforming anterior chamber may have been lower in the ACA group in order to prevent mechanical contact between the tube and the corneal endothelium, and/or contact between the crystalline lens and the corneal endothelium. ${ }^{22}$ Our third explanation is that there is a lower chance of peritubular filtration of aqueous in cases with CS implantation since the tunnel is longer (sclera and ciliary body tissues) when compared with ACA implantation (sclera tissue). This is in agreement with the findings of Maris $e t a^{22}$ who reported a lower incidence of shallow anterior chamber in patients with posterior segment AGV when compared with ACA AGV.

We observed one case of corneal decompensation in the ACA group and none in the CS group. Corneal endothelial failure is one of the most common long-term complications of ACA shunts. ${ }^{2-5}$ This can occur when the patient rubs their eyes or blinks intensely, when mechanical damage occurs due to the tube touching the cornea, when inflammation occurs as a result of the tube touching the iris or because of a chronic foreign body reaction to the tube. ${ }^{23,24}$ In a recent study, Koo et $a l^{25}$ found that the distance of the tube tip from the cornea is significantly associated with endothelial cell loss. Another hypothesis states that endothelial damage is due to jets of aqueous humor through the silicone tube caused by the heartbeat. Since the jet flow is fastest near the silicone tube, endothelial cells closer to the tube may be particularly affected. ${ }^{23}$ Implantation of the AGV through the CS may help to avoid damage to the corneal endothelium by shielding effect of the iris and preventing the above-mentioned jet flow effect.

The postoperative choroidal effusion ratio was similar between the two groups. There were two patients that showed tube erosion in the ACA group but none in the CS group. Tube erosion was successfully repaired using scleral patch tissue.

CS placement procedure can increase the intraocular inflammation in cases of uveitic glaucoma. Microscopic and continuous contact may occur between the tube and the iris, resulting in further intraocular inflammation. We observed marked inflammation in a patient with uveitic glaucoma after CS placement of the tube. The inflammation resolved following injection of tissue plasminogen activator into the anterior chamber.

Other less common complications included bleb encapsulation, tube obstruction, aqueous misdirection, tube migration, and phtisis bulbi. The incidence of these 
was similar in the two groups. We have not observed any cases of IOL dislocation in the CS group. This is probably because we implanted the tube through the ACA in patients with zonular weakness. ${ }^{26}$

Our study has some limitations. It is a retrospective chart review and a summary of our clinical experience rather than a controled randomized prospective study. The number of eyes differed in the two groups and eyes in the CS group were mostly pseudophakic or aphakic. Another shortcoming was that we did not have the data for corneal endothelial cell counts before and after the surgical procedure. Lens extraction causes endothelial cell loss, and seton implantation in pseudophakic and aphakic eyes may promote endothelial failure and bullous keratopathy in selected cases with borderline endothelial function. This might have affected the results of our study since CS group mostly comprised of cases with previous lens extraction. In further studies, it seems logical to compare endothelial cell loss between groups with the same lens status.

In spite of these limitations, we believe that our findings further support the idea that tube implantation through the CS in pseudophakic and aphakic eyes, or in patients with peripheral anterior synechia is a safe and effective procedure. Comparison of endothelial cell counts between ACA and CS tube insertion is required to confirm that the use of CS implantation can significantly reduce endothelial cell loss.

\section{Summary}

\section{What was known before}

- One of the main complications of glaucoma drainage device implantation into the anterior chamber angle is corneal endothelial decompensation. The frequency of corneal complications following GDD implantation with tube insertion into the ACA has been reported to be between 7 and $27 \%$.

\section{What this study adds}

- Our findings further support the idea that tube implantation through the ciliary sulcus in pseudophakic and aphakic eyes, or in patients with peripheral anterior synechia is a safe and effective procedure. This method may be better for preservation of the corneal endothelium.

\section{Conflict of interest}

The authors declare no conflict of interest.

\section{References}

1 Ramulu PY, Corcoran KJ, Corcoran SL, Robin AL. Utilization of various glaucoma surgeries and procedures in Medicare beneficiaries from 1995 to 2004. Ophthalmology 2007; 114: 2265-2270.
2 Topouzis F, Coleman A, Choplin N, Bethlem MM, Hill R, $\mathrm{Yu} \mathrm{F}$ et al. Follow-up of the original cohort with the Ahmed glaucoma valve implant. Am J Ophthalmol 1999; 128: 198-204.

3 Kook MS, Yoon J, Kim J, Lee MS. Clinical results of Ahmed glaucoma valve implantation in refractory glaucoma with adjunctive mitomycin C. Ophthalmic Surg Lasers 2000; 31: 100-106.

4 Wilson MR, Mendis U, Paliwal A, Haynatzka V. Long-term follow-up of primary glaucoma surgery with Ahmed glaucoma valve implant versus trabeculectomy. Am J Ophthalmol 2003; 136: 464-470.

5 Gedde SJ, Herndon LW, Brandt JD, Budenz DL, Feuer WJ, Schiffman JC. Surgical complications in the tube versus trabeculectomy study during the first year of follow-up. Am J Ophthalmol 2007; 143: 23-31.

6 Varma R, Heuer DK, Lundy DC, Baerveldt G, Lee PP, Minckler DS. Pars plana Baerveldt tube insertion with vitrectomy in glaucomas associated with pseudophakia and aphakia. Am J Ophthalmol 1995; 119: 401-407.

7 Eslami Y, Mohammadi M, Fakhraie G, Zarei R, Moghimi S. Ahmed glaucoma valve implantation with tube insertion through ciliary sulcus in pseudophakic/aphakic eyes. J Glaucoma 2014; 23: 115-118.

8 Sidoti PA, Mosny AY, Ritterband DC, Seedor JA. Pars plana tube insertion of glaucoma drainage implants and penetrating keratoplasty in patients with coexisting glaucoma and corneal disease. Ophthalmology 2001; 108: 1050-1058.

9 Arroyave CP, Scott IU, Fantes FE, Feuer WJ, Murray TG. Corneal graft survival and intraocular pressure control after penetrating keratoplasty and glaucoma drainage device implantation. Ophthalmology 2001; 108: 1978-1985.

10 Rumelt S, Rehany U. Implantation of glaucoma drainage implant tube into the ciliary sulcus in patients with corneal transplants. Arch Ophthalmol 1998; 116: 685-687.

11 Tello C, Espana EM, Mora R, Dorairaj S, Liebmann JM, Ritch R. Baerveldt glaucoma implant insertion in the posterior chamber sulcus. Br J Ophthalmol 2007; 91: 739-742.

12 Prata TS, Mehta A, De Moraes CG, Tello C, Liebmann J, Ritch R. Baerveldt glaucoma implant in the ciliary sulcus: midterm follow-up. J Glaucoma 2010; 19: 15-18.

13 Weiner A, Cohn AD, Balasubramaniam M, Weiner AJ. Glaucoma tube shunt implantation through the ciliary sulcus in pseudophakic eyes with high risk of corneal decompensation. J Glaucoma 2010; 19: 405-411.

14 Heuer DK, Barton K, Grehn F et al. Consensus on definitions of success. In: Sherwood MB, Grehn F (eds). Guidelines on Design and Reporting of Surgical Trials. World Glaucoma Association. KuglerAmsterdam, The Netherlands, 2008, pp 15-24.

15 Fluorouracil Filtering Surgery Study Group. Five-year follow up of the Fluorouracil Filtering Surgery Study. Am J Ophthalmol 1996; 121: 349-366.

16 Moon K, Kim YC, Kim KS. Ciliary sulcus Ahmed valve implantation. Kor J Ophthalmol 2007; 21: 127-130.

17 Broadway DC, Iester M, Schulzer M, Douglas GR. Survival analysis for success of Molteno tube implants. Br J Ophthalmol 2001; 85: 689-695.

18 Gedde SJ, Schiffman JC, Feuer WJ, Herndon LW, Brandt JD, Budenz DL. Treatment outcomes in the tube versus trabeculectomy study after five years of follow-up. Am J Ophthalmol 2012; 153: 789-803. 
19 Budenz DL, Barton K, Gedde SJ. Five-year treatment outcomes in the Ahmed Baerveldt comparison study. Ophthalmology 2015; 122: 308-316.

20 Wang YW, Wang PB, Zeng C, Xia XB. Comparison of the Ahmed glaucoma valve with the Baerveldt glaucoma implant: a meta-analysis. BMC Ophthalmol 2015; 15: 132.

21 Souza C, Tran DH, Loman J, Law SK, Coleman AL, Caprioli J. Long-term outcomes of Ahmed glaucoma valve implantation in refractory glaucomas. Am J Ophthalmol 2007; 144: 893-900.

22 Maris PJG, Tsai JC, Khatib N, Bansal R, Al-Aswad LA. Clinical outcomes of Ahmed glaucoma valve in posterior segment versus anterior chamber. J Glaucoma 2013; 22: 183-189.
23 McDermott ML, Swendris RP, Shin DH, Juzych MS, Cowden JW. Corneal endothelial cell counts after Molteno implantation. Am J Ophthalmol 1993; 115: 93-96.

24 Edelhauser HF, Geroski DH, Woods WD, Holley GP, Laniado-Schwartzman M. Swelling in the isolated perfused cornea induced by 12 (R) hydroxyeicosatetraenoic acid. Invest Ophthalmol Vis Sci 1993; 34: 2953-2961.

25 Koo EB, Hou J, Han Y, Keenan JD, Stamper RL, Jeng BH. Effect of glaucoma tube shunt parameters on cornea endothelial cells in patients with Ahmed valve implants. Cornea 2015; 34: 37-41.

26 Moreno-Montanes J, Velazques-Villoria A, Sabater AL, Salinas-Alamán A. Intraocular lens dislocation and tube shunt in the posterior chamber: a case report. BMC Ophthalmol 2015; 15: 63. 